\title{
It came from something awful: how a toxic troll army accidentally memed Donald Trump into office, by Dale Beran, 2019. St. Martin's Publishing Group. ISBN: 9781250189745,304 Pages
}

\author{
All Points Books, First Edition, 2019
}

Denise Burkert ${ }^{1} \cdot$ Stephan G. Humer ${ }^{1}$

Accepted: 3 May 2021 / Published online: 8 June 2021

(c) The Author(s) 2021

In It Came From Something Awful, Beran describes how platforms like 4chan were created, how a group of hacktivists like Anonymous started a worldwide digital revolution, and how all of this is linked to the Presidency of Donald Trump. 4chan, perhaps the world's most notorious Imageboard, can be described as one of the most shocking and at the same time most nihilistic websites of all time, besides some other very dark corners of the Darknet. To illustrate this state of mind, Beran offers many examples, for instance, a teenage boy called Stephen wanting to commit suicide by setting himself on fire while streaming it live on 4chan. (The victim was tellingly called "Toaster Steve" by the 4chan community afterwards.) Although some illustrations or screenshots of 4 chan chats are included in this work, Beran nonetheless describes the platform so well that the reader can imagine the undisplayed parts of nihilism and abysses of 4chan.

Besides some unique memes, Beran elaborates on related events and people involved in a very detailed way. Even people who were adolescents in the early 2000s, and attributed as active parts of the 4chan "movement", will still discover new connections and correlations through the graphic and abysmal presentations given by the author. The topic of Digital War and Misinformation, which is the integral aspect of the book, is generally presented in an appropriate and enlightening way. For instance, how the significant 4chan topic "child pornography", referred to as "CP", informed scandals such as Clinton's Pizzagate in 2016 (because "CP" could also stand for "cheese pizza"). Such small jokes on 4chan were so driven into the absurd that in the end even

Stephan G. Humer

stephan.humer@hs-fresenius.de

1 Berlin, Germany some of those involved in the joke thought Pizzagate was true.

In the early 2010s, 4chan became "depressed" and with its depression, 4chan was flooded with fascism and white supremacy. 4chan users saw themselves as NEETs (Not in Education, Employment, or Training) and therefore socalled beta males - as they are in their opinion obviously not alpha males. NEETs wished for a return to the 1950s, when white men had highly paid unionized jobs, could randomly summon cops to beat up People of Color and could have sex with a submissive and dutiful wife "with no concern for her pleasure". In such times, these 4chan users could envision themselves not "in their mothers' basement, broke and alone, but rather [as] men supplied with good jobs, houses, wives, cars, and dignity." Thus, parts of 4chan evolved into an Alt-Right habitat.

This book is not concerned with the technics of the platform. Beran occasionally provides some technical information, but this is not detailed enough to be interesting for tech nerds. Yet such prior technical knowledge is not required to find this work accessible. We would recommend this book for anyone with a broad interest in 4chan, trolls, right-wing movements, and the evolution of the presidency of Donald Trump in this context.

Beran certainly brings a wealth of experience to this work, including from participating in Anonymous' first protest against Scientology in 2008 as a reporter. Beran also interviewed several 4chan users.

It is now generally accepted that social media in general, and certain platforms such as Reddit and 4chan, can have a reinforcing effect in the direction of some extremist groups. However, people do not radicalize themselves in isolation and through exclusively by reading discussion contributions on specific platforms. Rather, polarization in general and 
extremism in particular occurs through a socialization process in a wider ecology via a complex mosaic of influences. Yet, Beran attributes considerable responsibility to platforms such as 4chan for the Trump's presidential election victory in 2016.

What is important is an appropriate assessment of the influence of digital and social media platforms in the round. 4chan may appear to many as one of these "game changers" in terms of spreading hatred and violence, but the reasons for radicalization, hate, and agitation in a modern society are more diverse and, in terms of its history, reach much deeper. There are fundamental social issues that must be resolved on the way to a more peaceful society. Digital platforms look tiny compared to this challenge. However, this does not mean that the book misses its purpose. We therefore strongly recommend this work for anyone who wants to gain a rich insight into the development of 4 chan and other notorious platforms.

Funding Open Access funding enabled and organized by Projekt DEAL.
Open Access This article is distributed under the terms of the Creative Commons Attribution 4.0 International License (http://creativeco mmons.org/licenses/by/4.0/), which permits unrestricted use, distribution, and reproduction in any medium, provided you give appropriate credit to the original author(s) and the source, provide a link to the Creative Commons license, and indicate if changes were made. The Creative Commons Public Domain Dedication waiver (http://creativeco mmons.org/publicdomain/zero/1.0/) applies to the data made available in this article, unless otherwise stated.

Denise Burkert, M. Sc., Assistant Coordinator Advanced Research Projects and Member, Research Cluster of Excellence on Terrorism/ Extremism (Joint Project MOTRA), Terrorism Research Network (Netzwerk Terrorismusforschung e. V.) Berlin, Germany.

Stephan G. Humer, Dr. phil., Professor and Director, Internet Sociology Department, Fresenius University Berlin. Chairman of the Board, Coordinator Advanced Research Projects and Member, Research Cluster of Excellence on Terrorism/Extremism (Joint Project MOTRA), Terrorism Research Network (Netzwerk Terrorismusforschung e. V.) Berlin, Germany. 